\title{
Interface studies in a Ti-6Al-4V/sigma fiber composite
}

\author{
D. UPADHYAYA, M.A. BAKER* ${ }^{*}$ C.M. WARD-CLOSE ${ }^{* *}$, P. TSAKIROPOULOS ${ }^{*}$ and \\ F.H. FROES \\ Institute for Materials and Advanced Processes, University of Idaho, Moscow, ID 83843, U.S.A. \\ * Department of Materials Science and Engineering, University of Surrey, Guildford, Surrey GU2 5XH, \\ U.K. \\ ${ }_{* *}^{*}$ Materials and Structures Dept. DRA Farnborough, Hants GU14 6TD, U.K.
}

\begin{abstract}
The paper reports results from an on going study of the interfaces in diffusion bonded Ti-6Al-4V/Sigma composites. This paper concentrates on the analysis of a composite in the as-received condition using Auger electron spectroscopy (AES) and scanning electron microscopy (SEM). The SiC based Sigma fiber has a tungsten core and a duplex coating of carbon (adjacent to the $\mathrm{SiC}$ deposit) and $\mathrm{TiB}_{\mathrm{x}}$. It is shown that boron from the $\mathrm{TiB}_{\mathrm{x}}$ layer diffused into the matrix and formed TiB needles. Carbon was detected in the $\mathrm{TiB}_{x}$ layer. Analysis of in-situ fracture surfaces has shown that the failure was initiated either within the carbon layers or at the $\mathrm{TiB}_{\mathrm{x}}$-matrix interface. The oxygen detected at the $\mathrm{TiB}_{\mathrm{x}}$-matrix interface influenced the fracture behavior of the composite.
\end{abstract}

\section{INTRODUCTION}

Silicon carbide fiber reinforced titanium alloy composites are being considered for many aerospace applications [1,2]. However, because of the reactivity of titanium with fibers at the fabrication stage and/or subsequent service temperatures the properties of the titanium matrix composites degrade and this has adversely affected their development [1-4]. At present, two types of continuous silicon carbide fiber, the SCS series (SCSi; $i=2,6,8,9$ ) and Sigma (SM1240 and SM1140) are available in single fiber form. Most previous work has concentrated on the SCS series fiber and limited information is available in the literature on the Sigma fiber reinforced titanium composites. Sigma (SM1240) fibers with a tungsten core are produced by a chemical vapor deposition process and have a duplex coating consisting of graphitic carbon (adjacent to the $\mathrm{SiC}$ deposit) and $\mathrm{TiB}_{\mathrm{x}}$. The other type of Sigma fiber (SM1140) has only carbon coating.

Recent studies on Ti-6Al-4V/Sigma(SM1240) composites have identified TiC and TiB as the reaction products [5-7]. It has also been suggested that the $\mathrm{TiB}_{\mathrm{x}}$ coating is unstable at temperatures above $770^{\circ} \mathrm{C}[8]$ and that the $\mathrm{TiB}_{2}$ particles interact with titanium from the matrix forming $\mathrm{TiB}$ needles at the interface between the matrix and $\mathrm{TiB}_{\mathrm{x}}$ coating $[5,7,9]$. The formation of TiB is thought to be further enhanced by the diffusion of carbon atoms from the carbon coating into the $\mathrm{TiB}_{\mathrm{x}}$ coating [7,8]. Diffusion of carbon atoms into the $\mathrm{TiB}_{\mathrm{x}}$ coating and subsequent formation of a thin $\mathrm{TiC}$ layer between the carbon and $\mathrm{TiB}_{\mathrm{x}}$ coatings has been reported [8]. The focus of this paper is to understand the diffusion phenomena and elemental distributions in a Ti-6Al-4V/Sigma(SM1240) composite. 


\section{EXPERIMENTAL}

The Ti-6Al-4V/Sigma(SM1240) composite used in this investigation was supplied by BP, Sunbury, $\mathrm{UK}$, in the form of 6-ply panels prepared by hot isostatic pressing of $80-100 \mu \mathrm{m}$ thick Ti-6Al-4V foils and $\mathrm{SiC}$ monofilament $\left(35 \%\right.$ by volume) at $900^{\circ} \mathrm{C}$ followed by cooling at $10-15^{\circ} \mathrm{C} / \mathrm{min}$. A typical section of the as-fabricated composite is shown in Figure 1. Specimens of the composite in the as-received condition were analyzed using scanning electron microscopy (SEM)and scanning Auger microscopy (AES/SAM) techniques. Cross-section samples for AES analysis were mechanically cut at $10^{\circ}$ from the fiber axis to increase the area of analysis. Machined faces were mechanically polished progressively from $75 \mu \mathrm{m}$ to $0.04 \mu \mathrm{m} \mathrm{Al}_{2} \mathrm{O}_{3}$ slurry until highly polished surfaces were achieved. The same polishing procedure was used for the preparation of SEM specimens. AES mapping was performed on a high resolution VG MA500 scanning Auger spectrometer. Auger maps were corrected for topographical effects using a (peakbackground)/background algorithm. Scanning electron micrographs were acquired on a Cambridge $\$ 250$ microscope.

\section{RESULTS AND DISCUSSION}

Figure 2 is a SEM micrograph of a specimen cut at $10^{\circ}$ from the fiber axis. The various regions and interfaces are labelled. Region $A$ represents the fiber and contains silicon and carbon as seen in the direct Auger spectrum in Figure 3A. The spectrum of the bulk fiber consists of three main signals at $92 \mathrm{eV}$ (low energy Si), $1610 \mathrm{eV}$ (high energy Si) and $272 \mathrm{eV}$ (carbon). Oxygen (signal at $512 \mathrm{eV}$ ) is also present.

Surrounding the $\mathrm{SiC}$ fiber is the carbon coating (region $\mathrm{B}$ ). Absence of silicon is seen in the Auger spectrum (Figure $3 \mathrm{~B}$ ). Furthermore, the carbon coating is free of any reaction products with titanium.

Adjacent to the carbon coating is the $\mathrm{TiB}_{\mathrm{x}}$ layer whose exact composition was rather difficult to determine. The Auger spectrum (Figure $3 \mathrm{C}$ ) shows the presence of carbon in this layer. Region $D$ is the matrix and the respective Auger spectrum is shown in Figure 3D.

The interfaces between the various layers were also analyzed by AES. Region $X$ represents the interface between SiC deposit and carbon coating. The direct Auger spectrum is similar to the bulk fiber. Region $\mathrm{Y}$ is the interface between carbon coating and $\mathrm{TiB}_{\mathrm{x}}$ layer. The Auger spectrum shows that boron as well as a small amount of titanium are present in this layer. The interface between the $\mathrm{TiB}_{\mathrm{x}}$ layer and the matrix is represented by region $\mathrm{Z}$. This layer shows the presence of carbon, boron, oxygen and titanium. The presence of carbon indicates that carbon has diffused through the $\mathrm{TiB}_{x}$ layer. The oxygen is detected in the $\mathrm{TiB}_{\mathrm{x}}$ layer and at the $\mathrm{TiB}_{\mathrm{x}}$ -

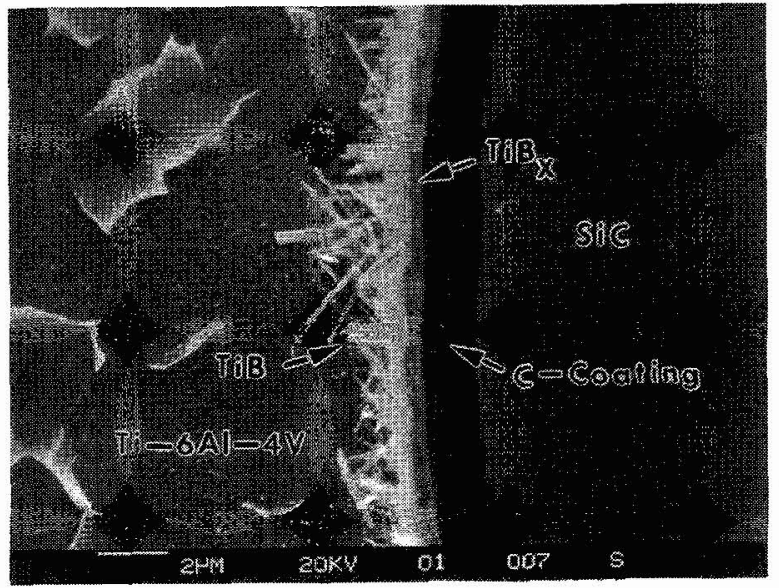

Figure 1. SEM micrograph of a polished transverse section of a etched as-received Ti-6Al-4V/Sigma composite. 


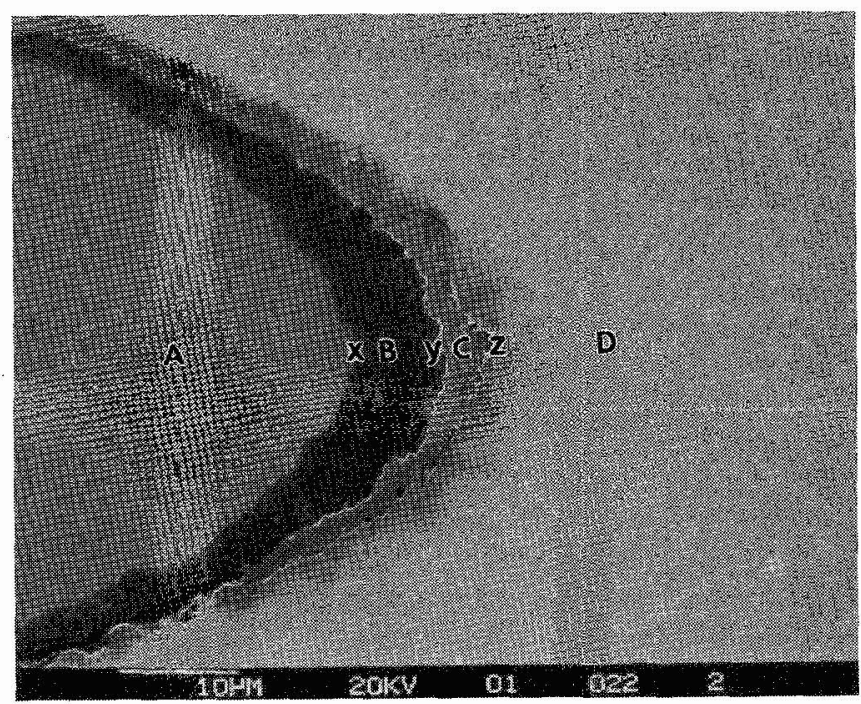

Figure 2. SEM micrograph of the Ti-6Al-4V/Sigma composite, denoting various regions (A to $D$ ), where $A$ is the fiber, $B$ is the carbon layer, $C$ is the $T_{i B}$ layer and $D$ is the matrix. $X$ is the interface between $A$ and $B, Y$ is the interface between $B$ and $C, Z$ is the interface between $\mathrm{C}$ and $\mathrm{D}$.
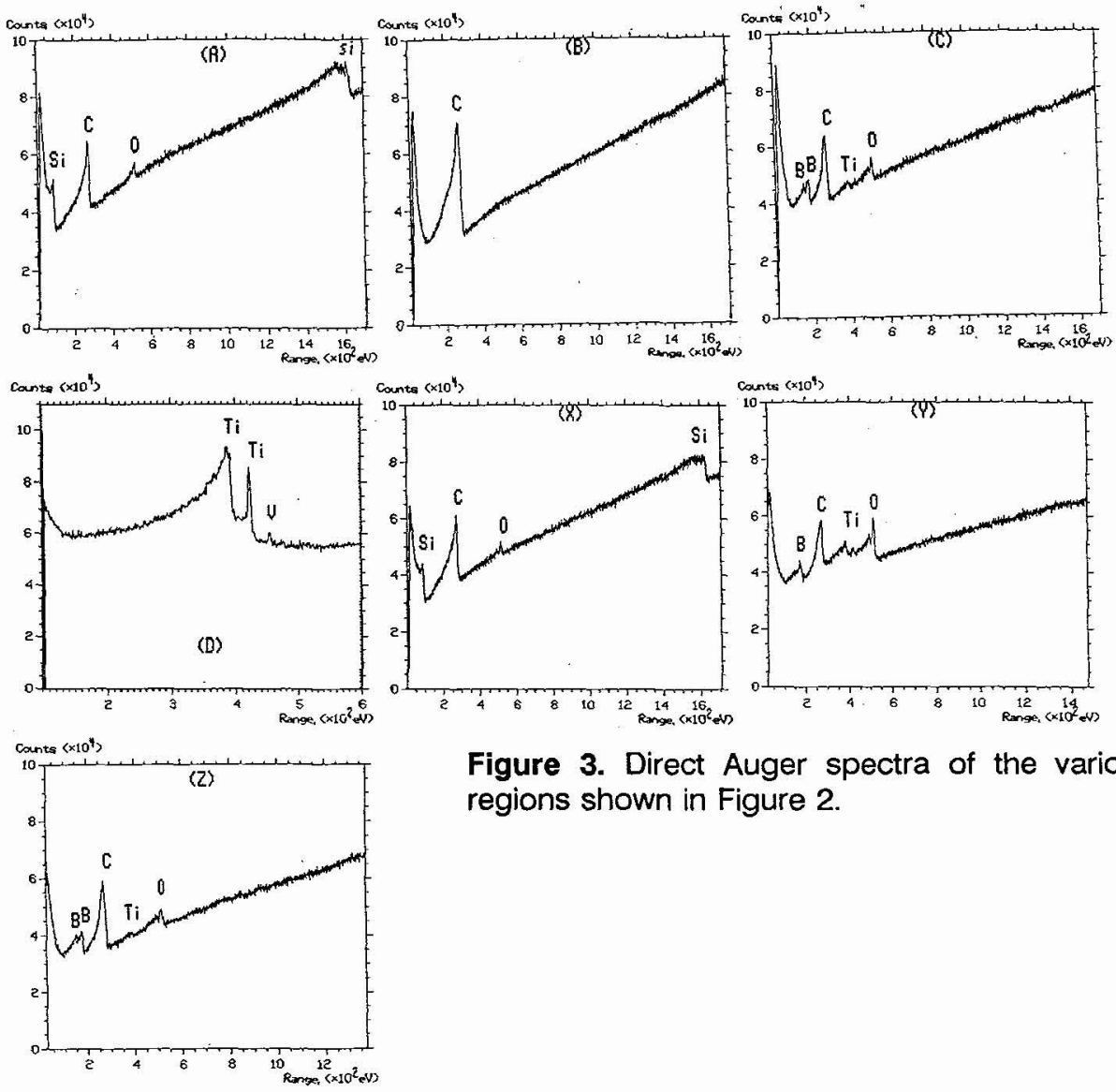

Figure 3. Direct Auger spectra of the various regions shown in Figure 2. 
matrix interface. The matrix spectra was acquired after 10 seconds of argon etching, showing that the carbon and oxygen contamination can be removed by argon etching. Further, the presence of carbon in the $\mathrm{TiB}_{x}$ layer was revealed by the Auger point analysis as discussed above. Figure 4 shows the Auger line profile of carbon, boron, silicon and titanium. The shape of the carbon profile is a characteristic diffusion profile showing that carbon is diffusing towards the $\mathrm{TiB}_{\mathrm{x}}$ layer. It is possible that the diffusion of boron into the matrix and the subsequent formation of TiB needles creates diffusion paths for carbon to diffuse towards the matrix. However, titanium diffusion into the carbon layer was not obvious.

Ti-6Al-4V/Sigma specimens were fractured in-situ in the Auger spectrometer using the three point bend test method. Figure 5 is a SEM micrograph of a fractured specimen along the fiber length with regions labelled FA, FB, FC and FD. The Auger spectra are shown in Figure 6 . It seems that the failure initiated either within the carbon layer (region FA) or at the $\mathrm{TiB}_{\mathrm{x}}$-matrix interface (region FC). Subsequent analysis of the three point bend test has suggested that the failure should initiate within the carbon layers. However, the failure initiation site is very much influenced by the alignment of the specimen and point of loading, both of which are extremely difficult to control in an AES. Presence of carbon in the region FB is evident, suggesting that carbon diffused into the $\mathrm{TiB}_{\mathrm{x}}$ layer.

Auger mapping of the in-situ fractured specimen revealed the presence of an oxide layer between the $\mathrm{TiB}_{x}$ layer and the matrix. Figure 7 shows high concentration of oxygen in the $\mathrm{TiB}_{\mathrm{x}}$ region compared to the matrix region. It is possible that the $\mathrm{TiB}_{\mathrm{x}}$ layer was oxidized during the deposition process. Presence of the oxide layer is also supported by the Auger point analysis (Figure 5, region $\mathrm{FC}$ ).

The presence of an oxide layer between the $\mathrm{TiB}_{\mathrm{x}}$-matrix interface may have influenced the fracture behaviour of the composite. Figure 8 shows the Auger analysis of boron for different surface conditions. The boron spectra of region $\mathrm{C}$ (Fig. $3 \mathrm{C}$ ) and region $\mathrm{Z}$ (Fig. 3Z) consist of two signals at $151 \mathrm{eV}$ and $174 \mathrm{eV}$. Evidently these spectra resemble those of natural oxide of boron (Figure 8). The Auger mapping of the in-situ fracture specimen also shows that a high amount of oxygen is present at the $\mathrm{TiB}_{\mathrm{x}}$-matrix interface compared to other regions.

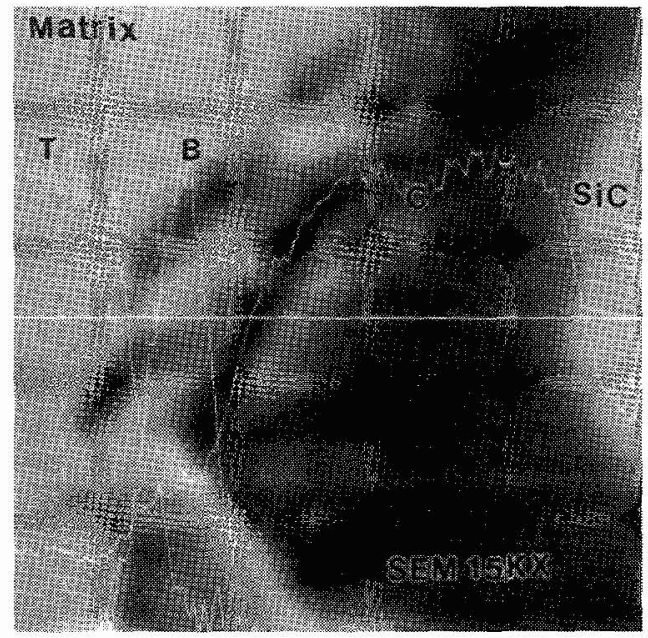

Figure 4. SEM micrograph with the Auger line profile of various elements in a Ti-6Al-4V/Sigma composite.

\section{CONCLUSIONS}

A Ti-6Al-4V/Sigma composite was investigated using Auger electron spectroscopy (AES/SAM) and scanning electron microscopy (SEM). Boron from the $\mathrm{TiB}_{\mathrm{x}}$ layer had diffused into the matrix and formed TiB needles. Carbon was detected in the $\mathrm{TiB}_{\mathrm{x}}$ layer and in the matrix. The diffusion 
of boron in the matrix and formation of TiB needles played an important role in the diffusion mechanism of carbon. It is suggested that boron diffusion into the matrix creates diffusion paths for the diffusion of carbon. Furthermore, in-situ fracture analysis has revealed that the fracture has occurred between the carbon layers. The results suggest that the $\mathrm{TiB}_{\mathrm{x}}$ coating probably oxidised during/after CVD deposition and an oxide layer was formed between the $\mathrm{TiB}_{\mathrm{x}}$ layer and matrix. This oxide layer has been considered as a probable site for fracture initiation.

Figure 5. SEM micrograph of a fractured Ti-6Al-4V/Sigma composite denoting various regions.
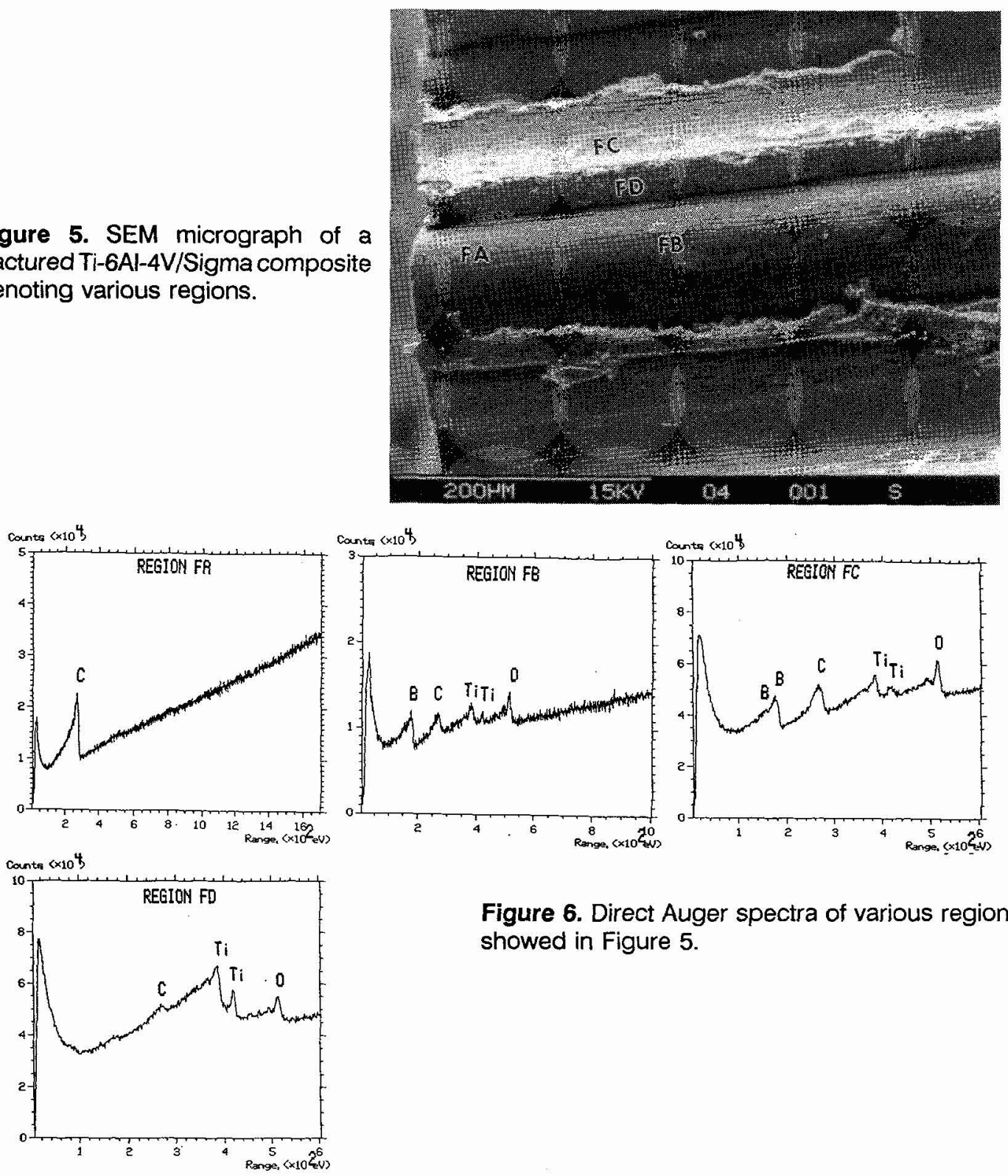

Figure 6. Direct Auger spectra of various regions showed in Figure 5. 


\section{ACKNOWLEDGEMENTS}

We would like to thank Prof. J. E. Castle for the provision of research facilities. This work was carried out at the Department of Materials Science and Engineering, University of Surrey, Guildford, UK.
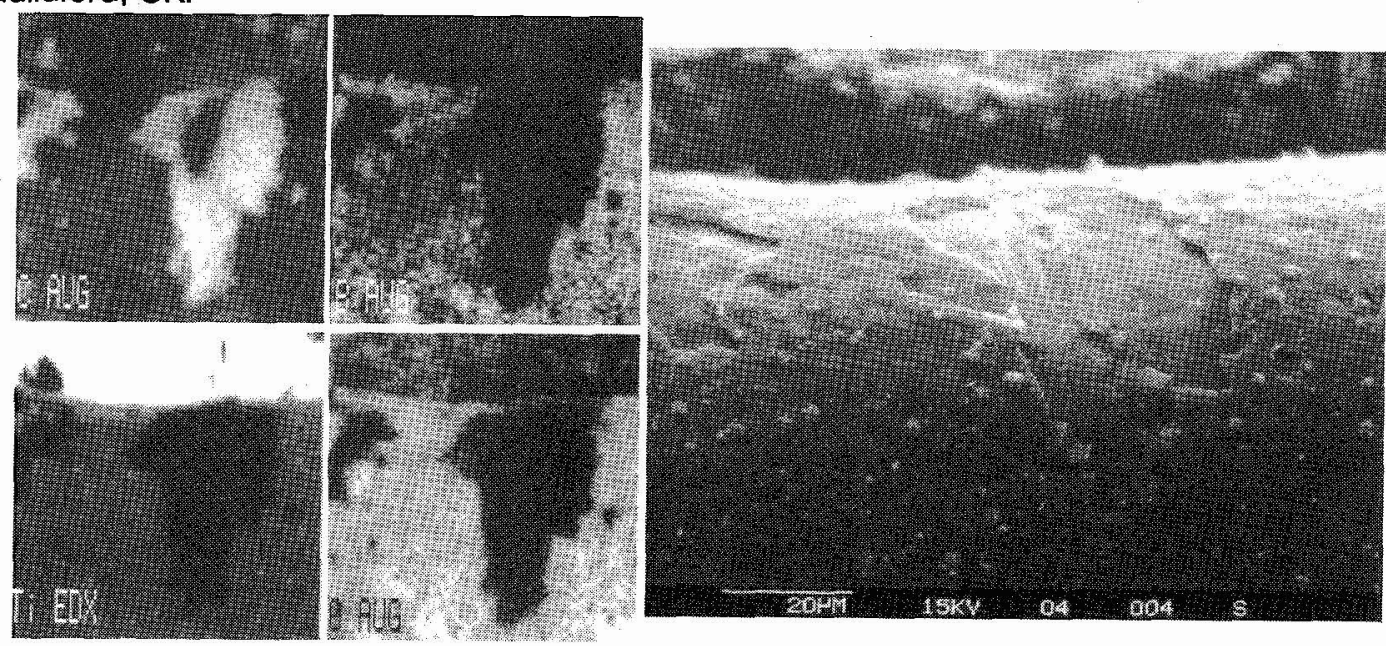

Figure 7. SAM/SEM images of the in- situ fractured Ti-6Al-4V/Sigma composite shown in Figure

6. Bright and dark field signify the rich and depleted regions of the element, respectively.

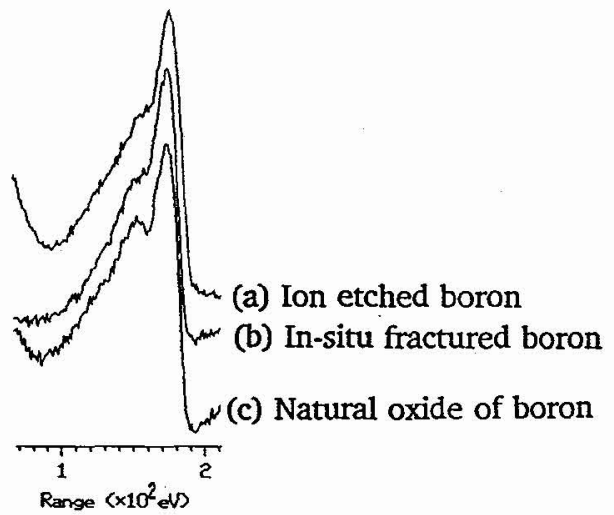

Figure 8. Auger spectra of boron recorded for different surface conditions, showing two peaks of natural boron oxide at $151 \mathrm{eV}$ and $174 \mathrm{eV}$.

\section{REFERENCES}

1. SMITH, P. R.and FROES,F. H., JOM, vol. 36, No. 3, (1984), 19.

2. LORETTO, M. H. and KONITZER, D. G., Met. Trans. A, vol. 21A, (June 1990), 1579.

3. PARTRIDGE, P. G. and WARD-CLOSE, C. M., Inter. Mater. Reviews, vol. 38, No. 1, (1993), 1. 4. WAWNER, F. E., "Fiber reinforcement for composite materials", Composite materials series, (ed. by Bunsell, A. R.), vol. 2, Elsevier publication, (1988), 371.

5. GUO, Z. X. et al., J. Microscopy, vol. 169, Pt 2, (Feb 1993), 279.

6. CHOY, K. L. et al., J. Microscopy, vol. 169, Pt 2, (Feb 1993), 289.

7. FERRARIS, M. et al., J. Mater. Sci., 28, (April 1993), 1983.

8. GUO, Z. X. et al., J. Microscopy, vol. 169, Pt 2, (Feb 1993), 269.

9. PRAGNELL, P. B. et al., in Conf. Proc., Advanced structural materials (ed. by Clyne, T. W. et al.), Institute of Materials, London, UK, vol. 2, (1992), 215. 